\title{
Zoonotic Pathogens in Ticks Collected from Livestock in Kenya
}

\author{
Mishael Oswe ${ }^{1,2}$, Rose Odhiambo², Beth Mutai', Nancy Nyakoe1, George Awinda1, \\ John N. Waitumbi ${ }^{*}$ \\ ${ }^{1}$ Basic Science Laboratory, US Army Medical Research Directorate-Kenya/Kenya Medical Research Institute, Kisumu, Kenya \\ ${ }^{2}$ Department of Biological Sciences, Egerton University, Njoro, Kenya \\ Email: *john.waitumbi@usamru-k.org
}

How to cite this paper: Oswe, M., Odhiambo, R., Mutai, B., Nyakoe, N., Awinda, G. and Waitumbi, J.N. (2018) Zoonotic Pathogens in Ticks Collected from Livestock in Kenya. Open Journal of Preventive Medicine, 8, 248-259.

https://doi.org/10.4236/ojpm.2018.88021

Received: April 17, 2018

Accepted: August 21, 2018

Published: August 24, 2018

Copyright (c) 2018 by authors and Scientific Research Publishing Inc. This work is licensed under the Creative Commons Attribution International License (CC BY 4.0).

http://creativecommons.org/licenses/by/4.0/ (c) (i) Open Access

\begin{abstract}
Ticks are reservoirs of a variety of pathogens including bacteria, viruses and protozoa. We used PCR to detect pathogens of public health importance in ticks collected from diverse regions of Kenya. 503 tick pools were collected from 982 cattle, 300 sheep and 379 goats that were presented for slaughter at major abattoirs in Nairobi and Mombasa. Tick DNA was screened by qPCR optimized for single-plex detection of Babesia microti, two-plex Coxiella burnetiilEhrlichia chaffeensis or Bartonella henselae/Borrelia recurrentis or three-plex for the non-human Babesia spp/Anaplasma phagocytophylum/Borrelia burgdorferi. Pathogen prevalence was calculated against tick type and the geographical origin. Computational analysis was performed with Graphpad prism 5. Out of 503 tick analyzed, 21\% (106) were positive for at least one pathogen. C. burnetii was the most abundant at $70 \%(74 / 106)$, followed by non-human Babesia at 17\% (18/106), 5\% (5/106) for B. burgdorferi, $7 \%(7 / 106)$ for other Borrelia species and $<1 \%(1 / 106)$ for E. chaffeensis and $A$. phagocytophylum. B. henselae and the human infective B. microti were not detected. Rh. pulchellus was the most promiscuous one in carrying pathogens: C. burnetti, Babesia, B. burgdorferi, E. chaffeensis and A. phagocytophylum. Non-human infective Babesia were detected in all ticks except Amblyomma. Four counties had 70\% of the infected ticks: Marsabit 25\% ( $\mathrm{n}=26 / 106), \mathrm{Ka}-$ jiado $17 \%$ (18/106), Wajir 16\% (17/106) and Narok 11\% (12/106). This study identified a number of tick-borne pathogens that cause febrile infections often confused with malaria. Follow-up research will be needed to determine prevalence in humans.
\end{abstract}

\section{Keywords}

Zoonosis, Borrelia, Babesia, Anaplasma, Coxiella 


\section{Introduction}

Many tick-borne zoonoses have symptoms that overlap with those of malaria. Amongst the tick borne zoonoses of public health importance are the protozoa that cause Babesiosis and Anaplasmosis, bacteria that cause lyme disease, rickettsiosis, Ehrlichiosis, Bartonellosis, Q fever and viral infections including tick borne encephalitis and Crimean-Congo hemorrhagic fever [1]. Babesiosis is caused by a red blood cell parasite, with two common species that frequently infect humans, namely B. microti and B. divergence [2]. Babesia $s p$ are close relatives of Plasmodium and can easily be mistaken for malaria on a thin blood film. Babesiosis is also a serious illness in wild and domesticated animals especially cattle, horses and dogs [3]. Babesia spp are transmitted by hard ticks such as Ixodes scapularis (black legged tick). In humans, the symptoms of babesiosis are similar to malaria, taking $1-8$ weeks to appear and include fever and chills, general weakness, gastrointestinal symptoms, headache, muscle and joint pains, haemolytic anaemia, jaundice, dark urine, shortness of breath, swollen spleen among others [4].

Anaplasmosis is primarily transmitted by the Ixode ticks that transmit the causative $A$. phagocytophilum bacterium. It was previously thought to be caused by an Ehrichia spp hence the name human granulocytic ehrlichiosis (HGE), but it has since been renamed human granulocytic anaplasmosis (HGA). Of the four development phases of tick life-cycle (egg, larvae, nymph, adult), nymphal and adult ticks are most frequently associated with transmission of anaplasmosis to humans. The bacteria infect neutrophils, causing changes in gene expression that prolong the life of these otherwise short-lived cells [5]. Typical symptoms include fever, headache, chills, and muscle aches which occur within $1-2$ weeks of a tick bite. Anaplasmosis is initially diagnosed based on symptoms and clinical presentation, and later confirmed by the use of specialized laboratory tests like PCR. The first line treatment is doxycycline.

Borreliosis (Lyme disease) is caused by a spirochete bacterium, Borrelia burgdorferi and B. afzelii transmitted through bites of Ixodes scapularis. The disease occurs in phases: an early localized disease with skin inflammation, disseminated disease with heart and nervous system involvement and the late disease that include motor and sensory nerve damage, brain inflammation and arthritis. The inflammation of the skin is accompanied by a generalized fatigue, muscle and joint stiffness, swollen lymph nodes and headache. Later phases of the disease affect the heart causing inflammation of heart muscles resulting in abnormal heart rhythms and heart failure. The nervous system can develop facial muscle paralysis (Bell's palsy), meningitis and confusion [6]. Diagnosis is by finding classic rash in people who have been in endemic areas. At later stages, antibody or nucleic acid test can be done to detect Lyme bacteria using ELISA and PCR [7]. Treatment involves the use of antibiotics such as oral doxycycline. So far in East Africa, only two cases of Lyme disease have been reported in Kenya [8].

$\mathrm{Q}$ fever is a zoonosis caused by Coxiella burnetii, an obligate gram-negative 
intracellular coccobacillus. It infects various hosts including humans, ruminants and pets and in rare cases reptiles, birds and ticks. The bacterium is excreted in urine, milk, faeces and birth products [9]. The birth materials contain a large number of bacteria that become aerosolized after drying. C. burnetii is highly infectious and even a few cells can cause disease [10]. It has a life cycle that produces spores hence can remain viable and virulent for months and infection can be acquired via inhalation or skin contact or sexual transmission. The pathogen can be transmitted to humans from ticks through salivary secretions and feces [11]. C. burnetii can infect people with no known contact with animals. Incubation period is 9 - 40 days. Its complications may include; acute respiratory distress, thrombocytopenia, endocarditis, spontaneous abortion, meningoencephalitis and chronic fatigue syndrome. About $60 \%$ of the patients are asymptomatic [12].

Human ehrlichiosis, also called monocytic ehrlichiosis, is caused by the Ehrlichia chaffeensis bacterium. Infected tick must attach for at least 24 hours for the infection to occur [1]. A survey for antibodies against $E$. chaffeensis in human sera from eight African countries indicated that human ehrlichiosis is common [4]. The disease can occasionally be life threatening or fatal and symptoms include fever, chills, muscle aches, weakness, headache, confusion, nausea, vomiting and joint pains. Incubation period is $1-3$ weeks after tick exposure. Laboratory diagnosis includes white blood cell count, low platelet count, abnormal liver enzymes, ELISA and PCR [13]. Treatment involves the use of tetracycline.

Bartonellosis is an infectious disease produced by intracellular bacteria of the genus Bartonella and can infect humans, mammals and a wide range of wild animals. The bacteria are carried by fleas, body lice and ticks [14]. The disease is often mild, but in some cases can cause serious disease. Early signs include fever, fatigue, headache, poor appetite and unusual streaked rash. Swollen glands are typical, especially around the head, neck and arms, gastritis, lower abdominal pain, and sore throat. Unusual manifestations like granulomatous conjunctivitis, neuroretinitis, atypical pneumonia or endocarditis may occur in small percentage of patients. Case fatality rate may exceed $40 \%$ if left untreated. Bacillary angiomatosis that may present as skin, subcutaneous and bone lesions are caused by $B$. henselae or $B$. quintana and peliosis hepatitis (caused by $B$. henselae) occur in people primarily infected with HIV [15]. Most cases of bartonellosis can be diagnosed PCR or serological tests using specific antigens.

This study determined the prevalence of important tick borne zoonoses that are transmitted by Kenyan ticks.

\section{Materials and Methods}

\subsection{Sampling}

The study was conducted under protocol number KEMRI SSC \# 1248 whose details have been published before [16]. Adult ticks were collected from 1661 li- 
vestock (982 cattle, 300 sheep and 379 goats) that were brought for slaughter houses in Nairobi (Kenya Meat Commission-KMC at Athi River and Dagoretti) and Mombasa (KMC Kibarani, Uwanja wa Ndege, Mariakani and Kasemeni). Ticks from the same animal were pooled together if they were of the same species based on taxonomic keys previously described [17]. A total of 503 tick pools and placed in the following species: Rhipicephalus appendiculatus (98 tick pools), R. pulchellus (148 tick pools), Boophilus annulatus (62 tick pools), Amblyomma gemma (58 tick pools), A. hebraeum (41 tick pools), A. variegatum (15 tick pools), other Amblyomma species (13 tick pools), Hyalomma truncatum (44 tick pools) and other Hyalomma species (24 tick pools).

\subsection{Detection of Pathogens by qPCR}

The DNA made from each tick pool was amplified by using primer sets and probes shown in Table 1. The assay was run either as single-plex (Babesia microti), two-plex (Coxiella burnetii/Ehrlichia chaffeensis) and Bartonella henselae/Borrelia recurrentis or three-plex (non-human Babesia spp./Anaplasma phagocytophylum/Borrelia burgdorferi). The unit reaction mix $(10 \mu \mathrm{L})$ contained 5.0 $\mu \mathrm{L}$ Quantitec 2X buffer (Applied Biosystem, California, USA), $0.5 \mu \mathrm{L}$ forward primer, $400 \mathrm{nMs}$ of reverse primer, $300 \mathrm{nMol}$ probe labeled with either FAM, VIC, CY3 or CY5 dye (all from Applied Biosystems, California, USA), 3 $\mu \mathrm{L}$ DNA template and sterile double distilled $\mathrm{H}_{2} \mathrm{O}$ to make to $10 \mu \mathrm{L}$. The assays were run in a 7500 Fast PCR machine (Applied Biosystem). The annealing temperatures were $60^{\circ} \mathrm{C}$ for 1 minute for the non-human Babesia spp./ Anaplasma phagocytophylum/Borrelia burgdorferi and Coxiella burnetiilEhrlichia chaffeensis, $56^{\circ} \mathrm{C}$ for a minute for Bartonella henselae/Borrelia recurrentis and $55^{\circ} \mathrm{C}$ for a minute for Babesia microti. Control samples were purchased from Fuller Laboratories (California) and were used at different dilutions (neat, 1:10 dilution and 1:100 dilution) to ensure that the target could be detected over a wide range. Non target control had PCR water.

\subsection{Data Analysis}

The study generated data that described the proportions and species of ticks that carried tick-borne pathogens and also described the pathogen prevalence and distribution in the different counties of Kenya. The data was routinely entered into a database created in Microsoft access. Continuous data was tested for Normality and descriptive statistics performed where appropriate. Computational analysis was performed with Graphpad prism 5 (GraphPad Software Inc. San Diego CA).

\section{Results}

\subsection{Pathogen Prevalence}

Out of 503 tick pools analyzed, 21\% (106/503) were positive for at least one pathogen. As shown in Figure 1, C. burnetii was the most abundant at a 
Table 1. The oligonucleotide sequences used in the study.

\begin{tabular}{|c|c|c|}
\hline Organism & Primers and Probe & Oligonucleotide Sequences 5'-3' \\
\hline $\begin{array}{c}\text { Borrelia } \\
\text { burgdorferi }\end{array}$ & $\begin{array}{l}\text { Bb Forward } \\
\text { Bb Reverse } \\
\text { Bb Probe }\end{array}$ & $\begin{array}{l}\text { CGAGTCTTAAAAGGGCGATTTAGT } \\
\text { GCTTCAGCCTGGCCATAAATAG } \\
\text { [NED]AGATGTGGTAGACCCGAAGCCGAGTG[BHQ2] }\end{array}$ \\
\hline $\begin{array}{c}\text { Anaplasma } \\
\text { phagocytophylum }\end{array}$ & $\begin{array}{l}\text { APMSP2 Forward } \\
\text { APMSP2 Reverse } \\
\text { APMSP2 Probe }\end{array}$ & $\begin{array}{l}\text { ATGGAAGGTAGTGTTGGTTATGGTATT } \\
\text { TTGGTCTTGAAGCGCTCGTA } \\
\text { [HEX]TGGTGCCAGGGTTGAGCTTGAGATTG[BHQ1] }\end{array}$ \\
\hline $\begin{array}{l}\text { Ehrlichia } \\
\text { chaffeensis }\end{array}$ & $\begin{array}{l}\text { ECH16SForward } \\
\text { ECH16SReverse } \\
\text { ECH16SProbe }\end{array}$ & $\begin{array}{l}\text { GCGGCAAGCCTAACACATG } \\
\text { CCCGTCTGCCACTAACAATTATT } \\
\text { [CY5]AGTCGAACGGACAATTGCTTATAACCTTTTGG } \\
\mathrm{T}[\mathrm{BBQ}]\end{array}$ \\
\hline $\begin{array}{l}\text { Babesia } \\
\text { microti }\end{array}$ & $\begin{array}{l}\text { BAB Forward } \\
\text { BAB Reverse } \\
\text { BAB Probe }\end{array}$ & $\begin{array}{l}\text { GGAAGTCTCGTGAACCCTTATCACTTAAA } \\
\text { GTAGGTGAACCTGCAGAAGGATCAAGC } \\
\text { [CY5]GGAAGGAGAAGTCGTAACAAGGTTTCC[BBQ] }\end{array}$ \\
\hline $\begin{array}{l}\text { Bartonella } \\
\text { henselae }\end{array}$ & $\begin{array}{l}\text { BARTICSForward } \\
\text { BARTICSReverse } \\
\text { BARTICS Probe }\end{array}$ & $\begin{array}{l}\text { TGCTTCGACTCCACTGTACGTC } \\
\text { CACCTGCTGCAATACATGCAAATG } \\
\text { TTGCAGCTTCATCAGGTGCTAATC }\end{array}$ \\
\hline $\begin{array}{l}\text { Coxiella } \\
\text { burnetti }\end{array}$ & $\begin{array}{l}\text { ICD-439 Forward } \\
\text { ICD-513 Reverse } \\
\text { Probe }\end{array}$ & $\begin{array}{l}\text { CGTTATTTTACGGGTGTGCCA } \\
\text { CAGAATTTTCGCGGAAAATCA } \\
\text { [6FAM]CATATTCACCTTTTCAGGCGTTTTGACCG[B } \\
\text { HQ-1] }\end{array}$ \\
\hline
\end{tabular}
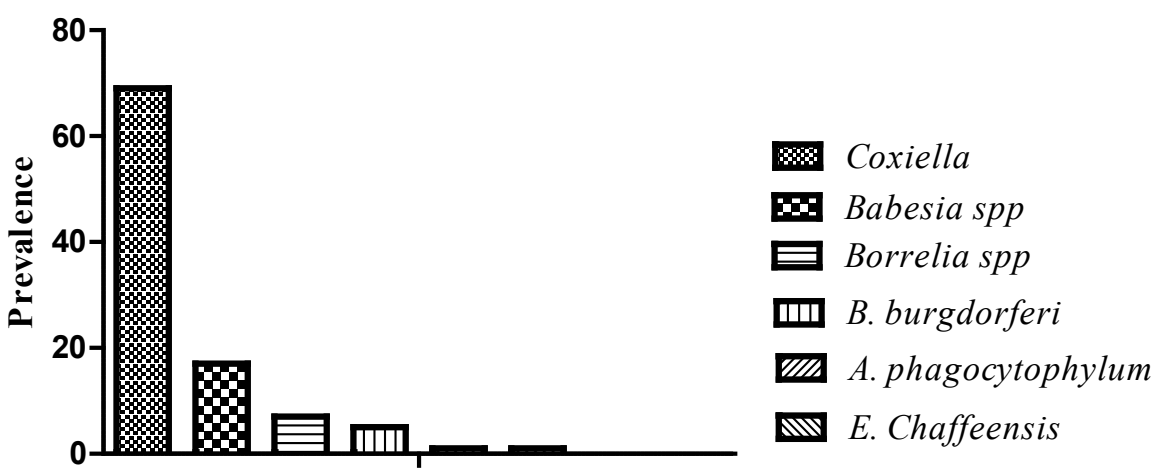

Figure 1. Overall prevalence rates for zoonotic pathogens in ticks. C. burnetii had the highest prevalence at 70\% (74/106), Babesia species 17\% (18/106), Borrelia species $7 \%$ (7/106), B. burgdorferi 5\% (5/106), A. phagocytophylum < 1\% (1/106), E. chaffeensis < $1 \%(1 / 106)$.

prevalence rate of $70 \%$ (74/106), of which $38 \%$ (28/74) were detected in Rhipicephalus pulchellus, 15\% (11/74) in A. hebraeum, 11\% (8/74) in $R$. appendiculatus, 12\% (9/74) in Amblyomma gemma, 8\% (6/74) in other Amblyomma species, 8\% (6/74) in Hyalomma truncatum, 7\% (5/74) in Boophilus annulatus and 1\% (1/74) in other Hyalomma species (Figure 2). Bartonella henselae and Babesia microti were not detected.

The prevalence of the non-human infective Babesia species was 17\% (18/106) with $33 \%(6 / 18)$ in $R$. pulchellus, $11 \%(2 / 18)$ in Rh. appendiculatus, $28 \%(5 / 18)$ in B. annulatus, $11 \%(2 / 18)$ in $H$. truncatum and $17 \%(3 / 11)$ in other Hyalomma species (Figure 3). 


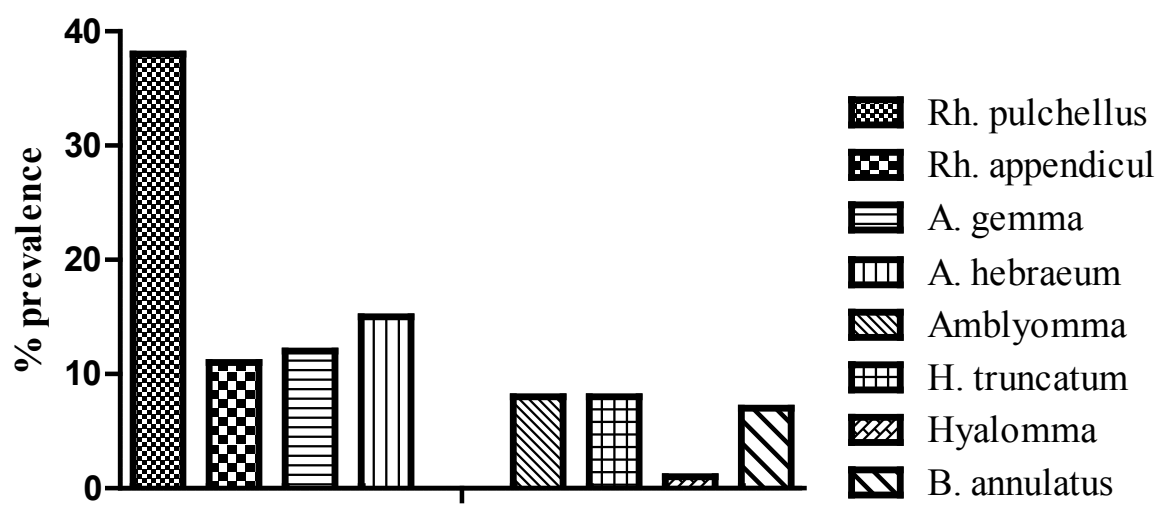

Figure 2. Infection rates of Coxiella burnetii in different tick species. Infection rate was highest in Rh. pulchellus (38\%), 11\% in Rh. appendiculatus, $12 \%$ in $A$. gemma, $15 \%$ in $A$. hebraeum, $8 \%$ in Amblyomma spp, $8 \%$ in H. truncatum, $1 \%$ in other Hyalomma spp, and $7 \%$ in $B$. annulatus $7 \%$. Infections were not detected in $A$. variegatum.

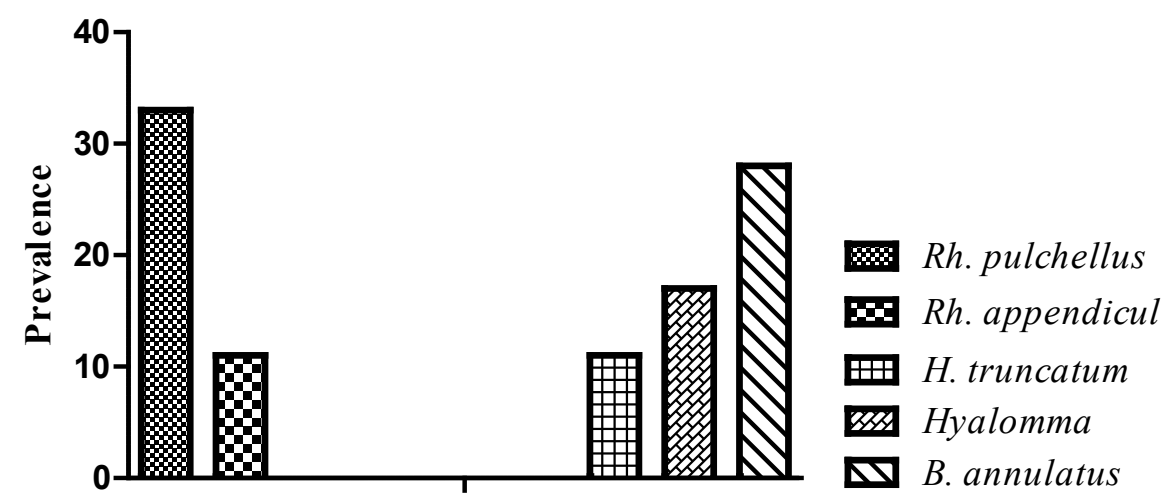

Figure 3. Prevalence rate of Babesia in different tick species. The human infective $B$. microti was not detected. The prevalence of other Babesia was $17 \%$, mainly detected in $R h$. pulchellus (33\%), Rh. appendiculatus (11\%), H. truncatum (11\%), Hyalomma spp (17\%), and $B$. annulatus (28\%). Infections were not detected in any of the Amblyomma ticks tested.

Infections of the human infective $A$. phagocytophylum and $E$. chaffeensis were very low and only single cases were detected in $R$. pulchellus.

As shown in Figure 4, B. burgdorferi was detected at a prevalence of 5\% (5/106) and only in B. annulatus, Rh. Pulchellus and A. hebraeumat prevalence rates of $40 \%, 20 \%$ and $20 \%$ respectively. Other Borrelia were detected in $R h$. pulchellus at $29 \%$, A. gemma at $57 \%$ and B. annulatus at $14 \%$. B. burgdorferi.

\subsection{Pathogen Distribution in the Kenyan Counties}

As shown in Table 2, of the 20 counties that contributed to the ticks examined, 14 had instances of ticks borne pathogens, and all were in the nomadic areas. Marsabit County had the highest prevalence of $25 \%$ (26/106), followed by Kajiado with $17 \%(18 / 106)$, Wajir $16 \%(17 / 106)$ and Narok, $11 \%(12 / 106)$. The lowest prevalence rate was recorded in Ewaso Nyiro, 2\% (2/106), Homabay 2\% $(2 / 106)$, Bomet and Uasin Gishu counties at $<1 \%(1 / 106)$ each. C. burnetii was 


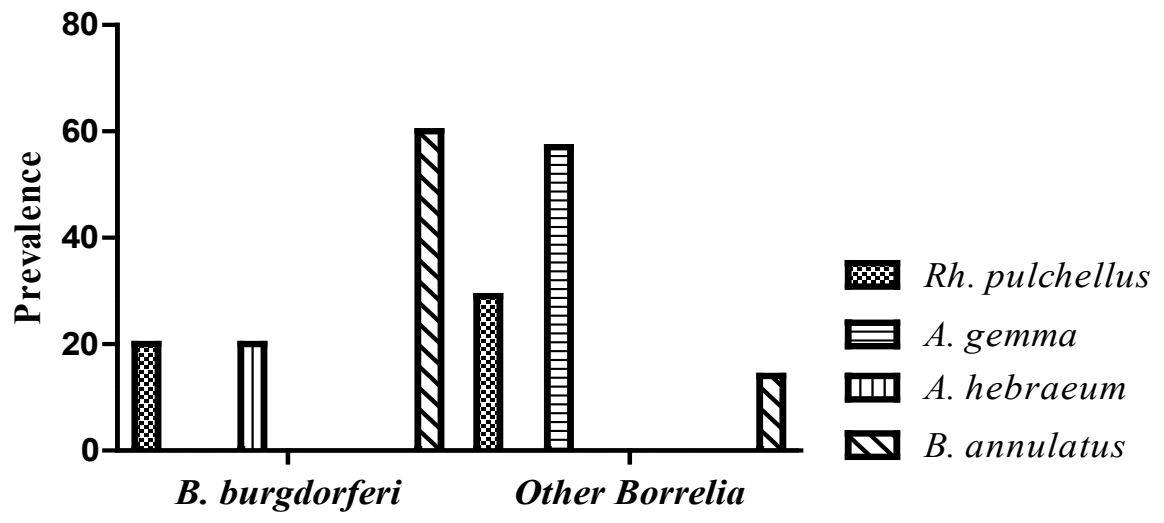

Figure 4. Prevalence rate of $B$. burgdorferi and other Borrelia in different tick species. $B$. burgdorferi were detected in $B$. annulatus, Rh. Pulchellus and A. hebraeum at prevalence rates of $40 \%, 20 \%$ and $20 \%$ respectively while other Borrelia had prevalence in $R h$. pulchellus at $29 \%$, A. gemma at $57 \%$ and B. annulatus at $14 \%$.

Table 2. Zoonotic pathogen prevalence rates in the Kenyan Counties.

\begin{tabular}{ccccccccc}
\hline County & livestock sampled & Coxiella & Babesia & B. burgdorferi & Other Borrelia & Anaplasma & Ehrlichia & Total \\
\hline Bomet & 40 & $1(1 \%)$ & $0(0 \%)$ & $0(0 \%)$ & $0(0 \%)$ & $0(0 \%)$ & $0(0 \%)$ & $1(1 \%)$ \\
Samburu & 31 & $1(1 \%)$ & $1(6 \%)$ & $0(0 \%)$ & $0(0 \%)$ & $0(0 \%)$ & $0(0 \%)$ & $2(2 \%)$ \\
Kajiado & 161 & $15(20 \%)$ & $2(11 \%)$ & $0(0 \%)$ & $1(14 \%)$ & $0(0 \%)$ & $0(0 \%)$ & $18(17 \%)$ \\
Machakos & 75 & $2(3 \%)$ & $1(6 \%)$ & $0(0 \%)$ & $0(0 \%)$ & $0(0 \%)$ & $0(0 \%)$ & $3(3 \%)$ \\
Migori & 21 & $1(1 \%)$ & $1(6 \%)$ & $1(20 \%)$ & $0(0 \%)$ & $0(0 \%)$ & $0(0 \%)$ & $3(3 \%)$ \\
Marsabit & 47 & $20(27 \%)$ & $0(0 \%)$ & $2(40 \%)$ & $3(43 \%)$ & $0(0 \%)$ & $1(100 \%)$ & $26(25 \%)$ \\
Kitui & 19 & $4(5 \%)$ & $0(0 \%)$ & $0(0 \%)$ & $0(0 \%)$ & $0(0 \%)$ & $0(0 \%)$ & $4(4 \%)$ \\
Laikipia & 20 & $4(5 \%)$ & $0(0 \%)$ & $0(0 \%)$ & $0(0 \%)$ & $0(0 \%)$ & $0(0 \%)$ & $4(4 \%)$ \\
Narok & 35 & $4(5 \%)$ & $7(39 \%)$ & $0(0 \%)$ & $0(0 \%)$ & $1(100 \%)$ & $0(0 \%)$ & $12(11 \%)$ \\
Nyandarua & 10 & $3(4 \%)$ & $0(0 \%)$ & $2(40 \%)$ & $2(29 \%)$ & $0(0 \%)$ & $0(0 \%)$ & $7(6 \%)$ \\
Homabay & 19 & $0(0 \%)$ & $2(11 \%)$ & $0(0 \%)$ & $0(0 \%)$ & $0(0 \%)$ & $0(0 \%)$ & $2(2 \%)$ \\
Taita Taveta & 40 & $6(8 \%)$ & $0(0 \%)$ & $0(0 \%)$ & $0(0 \%)$ & $0(0 \%)$ & $0(0 \%)$ & $6(6 \%)$ \\
Uasin Gishu & 20 & $1(1 \%)$ & $0(0 \%)$ & $0(0 \%)$ & $0(0 \%)$ & $0(0 \%)$ & $0(0 \%)$ & $1(1 \%)$ \\
Wajir & 21 & $12(16 \%)$ & $4(22 \%)$ & $0(0 \%)$ & $1(14 \%)$ & $0(0 \%)$ & $0(0 \%)$ & $17(16 \%)$ \\
Totals & & $74(100 \%)$ & $18(100 \%)$ & $5(100 \%)$ & $7(100 \%)$ & $1(100 \%)$ & $1(100 \%)$ & 106 \\
\hline
\end{tabular}

most prevalent in Marsabit 27\% (20/74), Kajiado 20\% (15/74) and Wajir 16\% $(12 / 74)$ and lowest $(<1 \%)$ in Bomet, Samburu, Migori and Uasin Gishu. Babesia species were most prevalent in Narok 39\% (7/18) and Wajir 22\% (4/18) with many areas reporting less than $1 \%$. B. burgdorferi was only detected in three counties: Marsabit 40\% (2/5), Nyandarua 40\% (2/5) and Migori 20\% (1/5) while the unspeciated Borrelia were detected in Marsabit 43\% (3/7), Nyandarua 29\% (2/7). The other counties recorded less than $1 \%$. Incidence of $A$. phagocytophilum and E. chaffeensis was low, each at $<1 \%$ and were detected in Narok $(1 / 106)$ and Marsabit (1/106) respectively. 


\section{Discussion}

The results show that ticks of the genus Rhipicephalus and Amblyomma were the dominant carriers of zoonotic pathogens with detection rate of $46 \%(49 / 106)$ and 29\% (31/106) respectively (Table 2 ). This is consistent with previous findings in which the two species were the dominant carriers of rickettsiae [16].

C. burnetii infection rates was the highest $(70 \%, 74 / 106)$ compared to $17 \%$ for Babesia spp, 7\% for Borrelia spp, 5\% for B. burgdorferi, $<1 \%$ for A. phagocyotophylum and E. chaffeensis. Among the tick species, the highest prevalence of the C. burnetii was recorded in Rh. pulchellus 38\% (28/74). This tick was also the highest carrier of other pathogens tested. It is possible that the significant differences in $C$. burnetii detection rates $(\mathrm{p}<0.0009)$ between tick species is based on the ticks mating system. [18] suggested that tick species with a more promiscuous mating system like $R h$. pulchellus could have a higher prevalence of infection as the infected individuals are more likely to come in contact with and infect the previously uninfected ticks through the sperms. C. burnetii was more prevalent in Wajir, Marsabit and Kajiado counties with prevalence rates of $28 \%(21 / 74), 27 \%(20 / 74)$ and 20\% (15/74) respectively (Table 2). According to CDC fact sheet on Q fever in Missouri (2008), contact with cattle and sheep are the main sources of naturally-occurring $C$. burnetii infections, hence herd to herd contact between animals from areas lead to spread of Coxiella infections.

The human infective B. microti was not detectable in the samples analyzed. This suggests that there is no significant risk of human babesia infections in Kenya. On the other hand, non-human Babesia spp was more prevalent especially in Rh. pulchellus, 33\% (6/18), Boophilus annulatus 28\% (5/18) ticks than Hyalomma spp 17 (3/18), $H$. truncatum 11\% (2/18) and Rh. appendiculatus $11 \%$ (2/18) ticks but none was detectable in Amblyomma ticks (Table 2 and Figure 3). Like in C. burnetii, Babesia infections were more prevalent in ticks obtained from cattle $(56 \%, 10 / 18)$ than sheep and goats, each with a prevalence of $22 \%$ (4/18). Narok had the highest number of ticks infected with other Babesia, 39\% (7/18), followed by $22 \%$ in Wajir (4/18), $11 \%$ in Homabay $(2 / 18), 11 \%$ in Kajiado (2/18), $5 \%$ in Migori (1/18), 5\% in Machakos (1/18) and Ewaso Nyiro 5\% (1/18). The higher prevalence of non-human Babesia in Narok and Wajir is probably as a result of free livestock movement and absence of tick control measures. This enhances the spread of tick borne pathogens [19].

As shown in Figure 4, the pathogen for human borreliosis, B. burgdorferi had a prevalence of $5 \%(5 / 106)$ while other Borrelia species had a prevalence of $7 \%$ (7/106), This data suggests that there is some considerable level of risk to $B$. burgdorferi in humans in Kenya. Only one sample tested positive for human infective $A$. phagocytophylum (Table 2). A similar research conducted in public parks in Italy did not detect any DNA of $A$. phagocytophylum in the tick samples screened [20]. This could suggest that the human pathogen is rare in Kenya. Likewise, only one tick sample contained $E$. chaffeensis DNA suggesting that the pathogen is very rare, hence of very low risk. There was no $B$. hensellae detecta- 
ble in the samples and studies show that this pathogen is rarely found in Ixodes ticks [11] [21].

This study found high prevalence of the tick-borne zoonoses in four counties of Kenya, namely Marsabit, Kajiado, Wajir and Narok. These counties also have large scale traditional livestock rearing activities and pastoralists that freely mix their animals enhancing the chance of ticks getting transferred to different animals and in turn increases the chances of transfer of the pathogens. Routine tick control measures are not carried out in these areas hence tick population keep increasing and in turn promote the population of these pathogens [22]. These counties are also contiguous to National parks with high wildlife populations. Sharing of habitats with wildlife could increase sharing of tick borne pathogens. Wajir and Marsabit counties are found in North-Eastern Kenya and they border Isiolo to the West and South respectively. The area has several game reserves such as Shad, Buffalo and other private game ranches [23]. In Kenya the game reserves allow communal grazing of livestock and wild animals and the subsequent habitat sharing increases likelihood of pathogen sharing. Cases of domestic canines frequenting forests and returning infested with ticks and suffering from tick borne rickettsioses have been reported [24]. Also, the geographical location of Wajir makes it to have links with Ethiopia, Somali and Southern Sudan. These countries have high densities of livestock that migrate across the Kenyan borders [25].

Kajiado County borders Nakuru County to the North in which the economic activities are agrarian and animal husbandry. To the North-West of Kajiado is Narok which is inhabited by the nomadic pastoral community. Narok has the Mau Narok forest reserve which has been encroached by humans resulting in fragmentation on previous forest areas and cultivation on the forest margins [19]. In the Mau Narok, forest reserve encroachment and fragmentation has increased agricultural activity, human settlement and animal husbandry. Kajiado also borders Makueni and Machakos to the North-East which are semi-arid areas with intense livestock rearing. The constant migration of domestic animals across county boundaries in search of pastures and water leads to the spread of tick borne zoonoses. In addition, these traditionally pastoral regions have no tick control programes.

\section{Conclusion}

In conclusion, a number of zoonoses were detected in ticks evaluated and were mainly carried by the Rhipicephalus and Amblyomma ticks. By country, the highest prevalence was in counties that practice traditional livestock rearing activities and/or those contiguous with national packs.

\section{Authors' Contributions}

Mishael Oswe conducted all experiments, analyzed data and drafted the manuscript. John Waitumbi conceived and designed the experiments and reviewed the manuscript. Rose Odhiambo was the university supervisor for Mishael Oswe. 
She participated in revision of the manuscript and provided important insights on the study design and data analysis. Nancy Nyakoe, George Awinda and Beth Mutai assisted in sample collection and Lab assays.

\section{Competing Interests}

The authors declare that they have no competing interests.

\section{Ethical Statement}

The study protocol was approved by the KEMRI Scientific and Ethical Review Committee (Protocol \# 1248).

\section{Disclaimer}

Material has been reviewed by the Walter Reed Army Institute of Research. There is no objection to its presentation and/or publication. The opinions or assertions contained herein are the private views of the author, and are not to be construed as official, or as reflecting true views of the Department of the Army or the Department of Defense. The investigators have adhered to the policies for protection of human subjects as prescribed in AR 70-25.

\section{Acknowledgements}

Funding for this study was obtained from the Armed Forces Health Surveillance Branch (AFHSB) and it's GEIS (Global Emerging Infections Surveillance and Response) Section.

\section{References}

[1] Jongejan, F. and Uilenberg, G. (2004) The Global Importance of Ticks. Parisitology, 129, 3-14. https://doi.org/10.1017/S0031182004005967

[2] Fritz, C.L., Kjemtrup, A.M., Conrad, P.A., Flores, G.R., Campbell, G.L., Schriefer, M.E., Vugia, D.J., et al. (1997). Seroepidemiology of Emerging Tickborne Infectious Diseases in a Northern California Community. Journal of Infectious Diseases, 175, 1432-1439. https://doi.org/10.1086/516476

[3] Burri, C., Dupasquier, C., Bastic, V. and Gern, L. (2011) Pathogens of Emerging Tick-Borne Diseases, Anaplasma phagocytophilum, Rickettsia spp., and Babesia spp., in Ixodes Ticks Collected from Rodents at Four Sites in Switzerland (Canton of Bern). Vector Borne and Zoonotic Diseases (Larchmont, N.Y.), 11, 939-944. https://doi.org/10.1089/vbz.2010.0215

[4] Maamun, J.M., Suleman, M., Akinyi, M., Ozwara, H., Kariuki, T. and Carlsson, H.-E. (2011) Prevalence of Babesia microti in Free-Ranging Baboons and African Green Monkeys. The Journal of Parasitology, 97, 63-67. https://doi.org/10.1645/GE-2391.1

[5] Lee, H.C., Kioi, M., Han, J., Puri, R.K. and Goodman, J.L. (2008) Anaplasma phagocytophilum-Induced Gene Expression in Both Human Neutrophils and HL-60 Cells. Genomics, 92, 144-151. https://doi.org/10.1016/j.ygeno.2008.05.005

[6] Cameron, D.J. (2004) Lyme and Associated Diseases Society Evidence-Based Guidelines for the Management of Lyme Disease. Expert Review of Anti-Infective Thera- 
py, 2, S1-13. https://doi.org/10.1586/14789072.2.1.S1

[7] Chang, Y.F., Novosel, V., Chang, C.F., Kim, J.B., Shin, S.J. and Lein, D.H. (1998) Detection of Human Granulocytic Ehrlichiosis Agent and Borrelia burgdorferi in Ticks by Polymerase Chain Reaction. The Journal of Veterinary Diagnostic Investigation, 10, 56-59. http://www.ncbi.nlm.nih.gov/pubmed/9526861 https://doi.org/10.1177/104063879801000110

[8] Jowi, J.O. and Gathua, S.N. (2005). Lyme Disease: Report of Two Cases. East African Medical Journal, 82, 267-269. https://doi.org/10.4314/eamj.v82i5.9318

[9] Kirkan, S., Kaya, O., Tekbiyik, S. and Parin, U. (2008) Detection of Coxiella burnetii in Cattle. The Journal of Veterinary Diagnostic Investigation, 32, 215-220. https://pdfs.semanticscholar.org/7b01/db2ca4a8bd72e73dd679237b7ad56d2ae5ca.p $\underline{\mathrm{df}}$

[10] Loftis, A.D., Reeves, W.K., Szumlas, D.E., Abbassy, M.M., Helmy, I.M., Moriarity, J.R. and Dasch, G.A. (2006) Surveillance of Egyptian Fleas for Agents of Public Health Significance: Anaplasma, bartonella, Coxiella, Ehrlichia, Rickettsia, and Yersinia pestis. American Journal of Tropical Medicine and Hygiene, 75, 41-48.

[11] Parola, P. and Raoult, D. (2001) Ticks and Tickborne Bacterial Diseases in Humans: An Emerging Infectious Threat. Clinical Infectious Diseases: An Official Publication of the Infectious Diseases Society of America, 32, 897-928. https://doi.org/10.1086/319347

[12] Panning, M., Kilwinski, J., Greiner-Fischer, S., Peters, M., Kramme, S., Frangoulidis, D. and Drosten, C. (2008) High Throughput Detection of Coxiella burnetii by Real-Time PCR with Internal Control System and Automated DNA Preparation. BMC Microbiology, 8, 77. https://doi.org/10.1186/1471-2180-8-77

[13] Petrovec, M., Sumner, J.W., Nicholson, W.L., Childs, J.E., Strle, F., Barlič, J., Avšič Županc, T., et al. (1999) Identity of Ehrlichial DNA Sequences Derived from Ixodes ricinus Ticks with those obtained from Patients with Human Granulocytic Ehrlichiosis in Slovenia. Journal of Clinical Microbiology, 37, 209-210.

[14] Maguiña, C. and Gotuzzo, E. (2000) BARTONELLOSIS: New and Old. Infectious Disease Clinics of North America, 14, 1-22. https://doi.org/10.1016/S0891-5520(05)70215-4

[15] Adamska, M. (2010) Bartonella spp. as a Zoonotic Pathogens Transmitting by Blood-Feeding Arthropods. Wiadomosci Parazytologiczne, 56, 1-9.

[16] Mutai, B.K., Wainaina, J.M., Magiri, C.G., Nganga, J.K., Ithondeka, P.M., Njagi, O.N., Waitumbi, J.N., et al. (2013) Zoonotic Surveillance for Rickettsiae in Domestic Animals in Kenya. Vector-Borne and Zoonotic Diseases, 13, 360-366. https://doi.org/10.1089/vbz.2012.0977

[17] Okello-Onen, J., Hassan, S.M. and Suliman, E. (1999) Taxonomy of African Ticks: An Identification Manual. International Centre of Insect Physiology and Ecology.

[18] Lockhart, A.B., Thrall, P.H. and Antonovics, J. (1996) Sexually Transmitted Diseases in Animals: Ecological and Evolutionary Implications. Biological Reviews of the Cambridge Philosophical Society, 71, 415-471. https://doi.org/10.1111/j.1469-185X.1996.tb01281.x

[19] Lambrechts, C. and Litoroh, M. (2007) Aerial Monitoring of Forest Boundaries.

[20] Corrain, R., Drigo, M., Fenati, M., Menandro, M.L., Mondin, A., Pasotto, D. and Martini, M. (2012) Study on Ticks and Tick-Borne Zoonoses in Public Parks in Italy. Zoonoses and Public Health, 59, 468-476.

https://doi.org/10.1111/j.1863-2378.2012.01490.x 
[21] Sanogo, Y.O., Zeaiter, Z., Caruso, G., Merola, F., Shpynov, S., Brouqui, P. and Raoult, D. (2003) Bartonella henselae in Ixodes ricinus Ticks (Acari: Ixodida) Removed from Humans, Belluno Province, Italy. Emerging Infectious Diseases, 9, 329-332. https://doi.org/10.3201/eid0903.020133

[22] Okuthe, O.S. and Buyu, G.E. (2006) Prevalence and Incidence of Tick-Borne Diseases in Smallholder Farming Systems in the Western-Kenya Highlands. Veterinary Parasitology, 141, 307-312. https://doi.org/10.1016/j.vetpar.2006.05.016

[23] Mati, B., Muchiri, J., Njenga, K., de Vries, F.P. and Merrey, D.J. (2006) Assessing Water Availability under Pastoral Livestock Systems in Drought-Prone Isiolo District, Kenya. International Water Management Institute.

http://www.iwmi.cgiar.org/Publications/Working_Papers/working/WOR106.pdf

[24] Rutherford, J.S., Macaluso, K.R., Smith, N., Zaki, S.R., Paddock, C.D., Davis, J., Rosenberg, R., et al. (2004) Fatal Spotted Fever Rickettsiosis, Kenya. Emerging Infectious Diseases, 10, 910-913. https://doi.org/10.3201/eid1005.030537

[25] Njoroge, E.M., Mbithi, P.M., Gathuma, J.M., Wachira, T.M., Magambo, J.K. and Zeyhle, E. (2000) Application of Ultrasonography in Prevalence Studies of Hydatid Cysts in Goats in North-Western Turkana, Kenya and Toposaland, Southern Sudan. The Onderstepoort Journal of Veterinary Research, 67, 251-255. 